\title{
SAFO EN LAS POETAS ROMÁNTICAS ESPAÑOLAS
}

SAPPHO IN THE ROMANTIC SPANISH POETESSES

$\mathrm{M}^{\mathrm{a}}$ Jesús Soler Arteaga Universidad de Sevilla

\section{Resumen:}

Safo fue una poetisa griega que posteriorment ha servido de inspiración para multitud de obras. En este artículo nos centramos en
analizar la importancia de la figura de Safo en las obras poéticas de las autoras románticas españolas, como Josefa Ugarte. Para ellas Safo supuso un espejo en el que reflejarse como mujer poeta en una sociedad patriarcal.

\section{Palabras claves:}

Safo, mujer, poema, Carolina Coronado

\section{Abstract:}

Sappho was a Greek poetess who has been an inspiration for many works afterwards. In this article we will focus on the analysis of the importance of the figure of Sappho in the poetical works of female Romantic Spanish writers, such as Josefa Ugarte. For them, Sappho was considered as a mirror in which they could be reflected as poetess in a patriarchal society.

\section{KEY WORD:}

Sappho, woman, poem, Carolina Coronado.
La historia de Safo está envuelta en la oscuridad, y confundida con la de otra Safo, griega también y poetisa célebre. Algunos autores, y entre ellos los que con más seguridad afirman que hubo dos Safos, Suda y Eliano. Dicen que la primera floreció en los tiempos de Alceo; pero no señalan la época de la segunda ni expresan con claridad cuál de las dos fue más célebre. A una de estas atribuyen por tradición costumbres deshonestas, y todo nos induce a creer que no es a la Safo autora de la Oda a Faón; porque está afirmado con el testimonio de escritores notables y por la inscripción que se lee distintamente sobre el mármol en la crónica de Paros... (Coronado, 1850, 178).

El personaje de Safo ha inspirado numerosos textos a lo largo de la historia. Sin embargo, el romanticismo es una de las etapas en las que este hecho se hace más evidente. La poeta griega cuya biografía está envuelta en el misterio despertó el interés de los escritores y sobre todo de las escritoras. En esta introducción nos detendremos en las causas que podemos aducir y seguidamente pasaremos a analizar diversos poemas de escritoras románticas españolas, que sintieron un gran interés por la autora de Lesbos. La cita con la que comenzamos pertenece al texto de Carolina Coronado "Los genios gemelos. Primer paralelo: Safo y Santa Teresa de Jesús", publicado en 1850 en el Semanario pintoresco español. En ella se hace referencia a un hecho documentado aunque no probado; la existencia de dos mujeres llamadas Safo, la primera la escritora, la segunda una cortesana y prostituta de la época. La escritora extremeña acude a dos fuentes históricas que recoge Aurora Luque en su edición de los poemas de Safo, se trata de Suda y Eliano, que constatan la existencia de las dos mujeres. Los escasos datos sobre su vida y la desigual suerte que sufrió su fama y su obra hizo que haya testimonios en los que se alaba a la escritora y otros, por ejemplo en los pertenecientes a los autores latinos, en los que se ridiculiza su figura. En cuanto a la homosexualidad de la escritora no es arriesgado decir, como sugieren distintos autores, que los poemas en los que se trata el erotismo homosexual, así como sus relaciones con sus amigas o sus discípulas, no son infundios. Ana Morilla Palacios en su análisis sobre la influencia de Safo en la autora cubana Mercedes Matamoros lo explica con gran claridad:

En la antigua Grecia el matrimonio estaba relacionado con la estirpe y la descendencia, mientras que el amor pasional pertenece a la esfera privada y no tenía como objetivo la procreación; dentro de este contexto hay que entender el papel de la bisexualidad como una condición natural a hombres y mujeres en un mundo que no podemos juzgar con parámetros actuales. La crítica hasta el siglo XX ha evitado o falsado la condición sexual de Safo. Actualmente nadie niega su bisexualidad: las destinatarias de su pasión son sus amigas, compañeras o alumnas, las cuales mantenían relaciones sexuales entre sí y con la poeta (Morilla, 2007: 285) 
Para las autoras románticas la explicación que ofrecía Carolina Coronado, apoyándose en los autores de la época, y la alabanza que hacía de ella como una mujer virtuosa, incluso citando frases atribuidas a la propia Safo, era la más aceptable en sus circunstancias: "Yo he recibido el amor de los placeres y el de la virtud en partes iguales. Sin ella nada es tan peligroso como la riqueza; y la felicidad consiste en la reunión de ambas" (Coronado, 1850, 178). La dedicación a la escritura no era vista con buenos ojos por parte de la sociedad. La misma Carolina Coronado expresó en numerosas ocasiones la frustración que suponía el ejercicio de las letras. Las autoras románticas en cualquiera de los géneros debían subvertir la imagen que de ellas como mujeres se había codificado, debían recurrir a la autoridad de su propia subjetividad y crear sus propias formas de representación, teniendo en cuenta que estas formas debían contenerlas a ellas mismas, es decir, tenían que crear tipos con los que ellas se identificaran y que a la vez erosionaran los existentes eligiendo entre atentar o no contra ellas mismas como sujetos sociales reales. En muchos casos las autoras se enfrentaron a la sociedad, a sus familias, que en algunos casos no deseaban que se dedicaran a la escritura, e incluso a ellas mismas, puesto que se autocensuraron por temor a las consecuencias que la publicación de ciertos textos podría acarrearles. Este es el caso de Carolina Coronado o de Amparo López del Baño, que censuraron poemas de contenido amoroso.

Un problema añadido era la falta de modelos. Como decíamos antes, estas autoras debían recurrir a su propia subjetividad, debido a la falta de autoras que pudieran sustentar el principio de autoridad. Safo encarnaría este papel a la perfección al ser poeta reconocida por sus contemporáneos, por el halo de misterio que despierta su figura y porque la existencia de dos personajes con el mismo nombre hace que la Safo poeta se desligue de todos los comportamientos censurables y se convierta en modelo de virtud en la poesía y también en su vida, por lo tanto imitarla daba licencia a estas autoras para escribir poemas de amistad, ${ }^{1}$ de amor e incluso de pasión desgarrada, si es

1 Marina Mayoral es autora de un artículo titulado "Las escritoras románticas: confusión de fórmulas y sentimientos" que se encuentra en el volumen Escritoras románticas españolas, coordinado po ella misma. En este texto estudiaba la amistad entre las autoras de este periodo a través de los poemas que se dedicaron en los que se canta a un sentimiento denominado amor, que bien puede identificarse con un amor espiritual y que ella explica de este modo:

La impresión equivoca que producen hoy muchos de estos poemas procede en gran parte del uso de un lenguaje y unas fórmulas expresivas tomadas de la poesía erótica masculina y que por su reiteración hay que considerar tópicos. Así nos encontramos con que se llaman unas a otras "vida mía", "ángel mío", "alma mía", "hermosa mía", "mi bien", y utilizan expresiones como "abrazarse con pasión", o el adjetivo "ardiente" para calificar sus manifestaciones de cariño. A eso hay que añadir cierta ambigüedad en la índole misma de los sentimientos expresados. Las mujeres escritoras parecen encontrar en el trato con otras mujeres una complacencia y una afinidad espiritual que no se da en su relación con los hombres y provoca en ocasiones un entusiasmo sentimental que si no es enamoramiento lo parece... (Mayoral, 1989: 44). para cantar la pasión de la autora griega, cuyo suicidio también deja de ser reprobable. Así lo explica Carolina Coronado en su texto "Los genios gemelos":

Safo fue a Leucades a buscar remedio contra su pasión desgraciada. Tres oráculos había consultado y estaban conformes. La adivina Manto se lo había predicho. Un sacrificio que se consagra a un dios y que era aprobado por los oráculos y bendecido por los sacerdotes, no era en Grecia un crimen sino una virtud heroica. Safo no fue, no pudo ser criminal sino con relación a nuestras doctrinas, según la religión que desgraciadamente profesaba, por no conocer la luz del catolicismo, Safo descendió a los mares para subir al Olimpo (Coronado, 1850, 178).

En el siglo XIX la obra de Safo era bien conocida, como explica Marta González González en su artículo “Versiones decimonónicas en castellano de la Oda a Afrodita (Frg. 1 Voigt) y de la Oda a una mujer amada (Frg. 31 Voigt) de Safo". En este artículo menciona algunas traducciones que fueron de gran importancia para que la obra de la autora de Lesbos se difundiera. Del siglo XVIII nombra la traducción de los hermanos José y Bernabé Canga Argüelles que publicaron en 1797 una colección titulada Obras de Sapho, Erinna, Alcman, Stesicoro, Alceo, Ibico, Simonides, Bachilides, Archiloco, Alpheo, Pratino, Menalipides. Traducidas del griego en verso por D. Joseph y D. Bernabé Canga Argüelles y en ese mismo año también apareció Poesías de Saffo, Meleagro y Museo, traducidas del griego por D. Joseph Antonio Conde. En el siglo XIX el primer texto es de 1832 Anacreonte, Safo y Tirteo, traducido del griego en prosa y verso por don José del Castillo y Ayensa, ${ }^{2}$ el siguiente es el de 1838 publicado en El Museo de las familias por A. Bergnes de las Casas, en 1878 Marcelino Menéndez Pelayo traduce algunos poemas de Safo en su obra Estudios poéticos, en ese mismo año Víctor Balaguer publicó la tragedia titulada Safo y de 1884 es Antiguos poetas griegos. La musa helénica. Traducido en verso por D. Ángel Lasso de la Vega. Finalmente Marta González cita dos textos de gran interés, el "Soneto imitando a una oda de Safo" de Gertrudis Gómez de Avellaneda, al que nos referiremos más adelante, y "Los genios gemelos" de Carolina Coronado, del que ya hemos extraído algunas citas. Para la investigadora, ambos textos demuestran el conocimiento que ambas autoras tenían de la traducción francesa de Boileau y en el caso de Gertrudis Gómez seguramente también era conocido el libreto de ópera de Emphis y Cournol, Sapho, tragédie lyrique en trois actes (París, 1818).

La aparición de estos poemas, como justifica Mayoral, se debe a la afinidad que las escritoras de este periodo encontraron entre sus iguales, puesto que las experiencias que compartían eran las mismas y entre ellas se dio en muchos casos un apoyo y aliento que no recibían de los hombres. Si las autoras tuvieron noticia de la relación de Safo y sus discípulas debió ser, al igual que el resto de su biografía, acorde a la moral romántica y un motivo más para que las escritoras románticas escribieran esto poemas con toda normalidad.

2 Marta González aclara que el autor demuestra conocer las traducciones de los autores franceses como las de Tanneguy Le Fèvre, la de Anne Le Fèvre Dacier y la de Boileau. 
También debemos reseñar las aportaciones de Óscar Barrero en su artículo "Imágenes de Safo en la literatura española (II). El Romanticismo", ${ }^{3}$ en el que recoge los datos aportados por Marta González y añade nuevos testimonios que nos ayudan a comprender cómo era el conocimiento que se tenía en el siglo XIX de Safo. Entre esas nuevas referencias están el estreno Saffo, (ópera seria en tres actos, con letra de Cammanaro y música de Paccini) el 9 de agosto de 1842, que a partir de junio del año siguiente siguió representándose y sirvió de inspiración y modelo para otras óperas, entre las que destacan las de Charles Gounod y Jules Massenet. Otra referencia importante es la publicación en el Semanario pintoresco español de una semblanza de Safo. Este artículo, que hemos mencionado anteriormente, pertenece a un proyecto muy amplio en el que se buscaba ver la trascendencia de la obra de la poeta griega en la literatura española durante los siglos XVIII y XIX, en cuanto a los autores que menciona se refiere a los citados por Marta González y añade estos nombres:

Por entonces Safo era, pese al escepticismo de Feijoo, más pasto de la leyenda que de la Historia. La citan, por ejemplo, Montengón, Leandro Fernández de Moratín y Quintana, aunque fueron Cienfuegos, María Gertrudis de Hore y María Rosa Gálvez quienes más espacio le dedicaron en sus obras. El repaso histórico termina con un texto de Arriaza y la conclusión de que Safo no era una figura desconocida en la España del siglo XVIII, pero no tanto por su obra y su personalidad histórica como por la leyenda creada en torno a ella (Barrero: 2005:pág. 1).

De hecho en María Gertrudis de Hore ha señalado la crítica un romanticismo incipiente más por su biografía que por su poesía, en la que destacan las anacreónticas de estilo rococó con su agitado ritmo musical, su lenguaje vitalista, sus recursos formales característicos (adjetivación, diminutivo, ornamentación mitológica; verso breve). Entre su producción destacan los poemas amorosos en ocasiones cargados de sensualidad y erotismo. Nosotros nos detendremos en uno de los poemas que recogen una referencia a Safo, en el que como se puede apreciar M. ${ }^{\underline{a}}$ Gertrudis de Hore se acerca a las poetas románticas:

\section{Sabré desesperada}

borrar como conviene

cual la de Mitilene

poetisa desgraciada,

la culpa de vivir enamorada.

\section{EL SIGLO XIX}

La primera mitad del siglo XIX estuvo marcada por el desarrollo de dos movimientos fundamentales: el liberalismo y el romanticismo. Comenzaremos teniendo en cuenta

3 En el segundo apartado menciona la obra teatral de Balaguer y los textos de Pascual de Sanjuán, de Menéndez Pelayo y de Fernández Merino. que el romanticismo es un movimiento de límites imprecisos. Las fechas de iniciación y de conclusión del periodo romántico han planteado numerosas dificultades. Así, Guillermo Díaz-Plaja (1980) reunía en su estudio del romanticismo español las fechas propuestas por el Marqués de Valmar, que situaba el "límite moral" del siglo XVIII en la invasión napoleónica de 1808, también la de Menéndez Pelayo, que consideraba que el siglo XIX no había comenzado para la literatura y la ciencia española antes de 1834, así como la opinión del padre Blanco García, que encontraba ambas fechas demasiado retrasadas. Marina Mayoral, en cambio, (1990) considera que las fechas aproximadas que comprenden el periodo romántico son 1830-1870. Gracias a determinados factores, entre los que debemos mencionar el desarrollo de la prensa periódica, durante el siglo XIX se produjo la aparición de numerosas escritoras en el panorama literario, autoras que según los estudios bibliográficos que emplea Marina Mayoral en la introducción a la obra Escritoras Románticas españolas, que ella misma coordinó, se puede afirmar que sobrepasan el millar. Sin embargo, son escasísimos los datos que tenemos tanto sobre ellas como sobre sus obras. Por otra parte, Susan Kirkpatrick comenzaba su estudio sobre las autoras románticas españolas entre 1835-1850 con la afirmación de Rosa Chacel: “En España no hubo romanticismo". La autora americana la tomaba como punto de partida para inmediatamente aclarar que sus conclusiones eran "contrarias a la convicción de Chacel de que la expresión femenina de la sensibilidad romántica no apareció en España antes del siglo XX" (Kirkpatrick, 1991: 11). No obstante, hemos reservado para finalizar las conclusiones de Díaz-Plaja por parecernos las más acertadas:

He aquí lo que únicamente puede afirmarse a las luz de nuestros conocimientos actuales: o el Romanticismo es una constante de la historia de la cultura, y en este caso debemos buscar su influencia, visible o subterránea, a lo largo de todos los siglos, o bien es un fenómeno específico de determinado periodo; entonces deberemos advertir en él una larga época de preparación que, sin exagerar, podemos señalar por todo el siglo XVIII, una época de florecimiento mucho más breve de lo que se cree en general, y un período de liquidación, que se inicia a mediados del siglo XIX y que dura -con el fin de siglo- hasta 1914 (Díaz-Plaja, 1980: 31-32).

La autora americana empleaba también unos límites lo bastante amplios como para establecer tres generaciones de autoras románticas. A la primera generación le correspondió la tarea de acomodar el lenguaje poético a las nuevas necesidades, se trataba de autoras nacidas entre 1811 y 1821 y que comenzaron su andadura en 1840 : Gertrudis Gómez de Avellaneda, Josefa Massanés y Carolina Coronado. La segunda generación está dominada por el triunfo del estereotipo femenino del ángel del hogar; a ella pertenecen las autoras que comenzaron a publicar entre 1850 y 1868: Pilar Sinués, Robustiana Armiño y Josefa Estévez. La tercera generación, a la que pertenecen las 
autoras nacidas después de 1850, tenían una educación más cuidada, que les permitía no solo cultivar la poesía o la prosa, sino dedicarse a otros campos como el ensayo. La oleada romántica estaba terminando, sin embargo las autoras pertenecientes a esta generación continuarán la tradición que ya habían modificado Rosalía de Castro o Gustavo Adolfo Bécquer en los que la crítica ve un adelanto de corrientes venideras.

En cuanto al liberalismo, debemos recordar que la teoría liberal consideró al yo como sujeto racional neutro en cuanto al sexo, sin estar sometido por la naturaleza a ninguna autoridad. Esta nueva consideración del yo dio lugar a nuevos modos de representación. De aquellas transformaciones culturales y económicas surgió una reestructuración de los modos de vida y la diferenciación drástica entre dos ámbitos: el privadoy el público; esto podía apreciarse en una importanteinstitución social:la familia. Los cambios en el modelo familiar y la teoría liberal no tuvieron un correlato ni en la consecución de la igualdad ni para el feminismo, que había surgido con la Ilustración y la Revolución francesa. La nueva interpretación de la mujer y particularmente del cuerpo femenino propuesta por la Ilustración y por Rousseau contribuyó a desarrollar una ideología típicamente burguesa sobre la mujer y las prácticas sociales correspondientes. Esta imagen estaba limitada a los deberes familiares y sobre todo a la maternidad y fue el ideal aceptado.

Esta diferenciación sexual era real en la práctica y circunscribía a la mujer burguesa en un círculo cerrado y pequeño en el que la dominación política masculina era un hecho, además esto tuvo consecuencias contradictorias en el discurso de la subjetividad. El movimiento romántico tenía un carácter introspectivo, dado el compromiso de los románticos con el sujeto individual y con su intención de convertirlo en un punto de vista y consecuencia de esto fue que descubrieron y describieron el mundo y la intimidad con su reescritura. La literatura romántica prestó atención a los procesos psicológicos, a los estados del yo y a sus impulsos, incluidos los libidinosos, y consiguió sacar a la luz las complejidades de la intimidad con la convicción de que éstas eran un reflejo de las complejidades del universo. El yo que representaban los románticos era un sujeto en el proceso de construirse a sí mismo, en constante búsqueda, independiente y ordenador que relaciona arte y experiencia y se identifica con tres arquetipos fundamentales: el transgresor prometeico, el individuo superior y alienado y la conciencia autodividida. Cada uno de ellos da lugar a visiones distintas: la irónica, la sublimación de la frustración del deseo, la separación radical entre subjetividad íntima y mundo exterior, la identificación de un sujeto alienado con la naturaleza, etc. Todas estas reacciones implicaban un escapismo hacia el interior para buscar un punto de partida desde el que comprender y dominar la realidad.

Las formas de representación románticas suponían un conflicto para las mujeres escritoras que no podían asumir la oportunidad que les ofrecían para desvelar la experiencia personal y el lenguaje cotidiano, por tanto no podían identificarse con el sujeto creador masculino y tampoco con el objeto femenino que éstos reproducían. Las soluciones que las autoras aportaron pasaban por el cuestionamiento del yo romántico paradigmático y por la rebeldía hacia el modelo del ángel doméstico. La tradición romántica identifica a la mujer con la otridad, con la naturaleza vista alternativamente de forma positiva o negativa, es decir, como la fuente de la vida o el fin de la misma. La subjetividad femenina podía identificarse con la naturaleza o presentarse como una naturaleza afeminada, pero que nunca le pertenecía; la diferenciación sexual dotaba a las mujeres de una subjetividad propia, se les concedía este poder pero a cambio de que redujeran sus deseos:

Como encarnación de los ideales puros de las clases medias en el siglo XIX se admiraba a las mujeres por su superioridad a todos los deseos mundanos. El ánge de la casa victoriano, descrito como absolutamente carente de deseo sexual, tan sumamente delicado como para ser débil, deseoso no solo de ser dependiente sino de cultivar y demostrar esa dependencia, tenía que estar absolutamente liberado de todo conocimiento corruptor del mundo material-y materialista. Po en su propia esfera la mujer era la reina (Poovey, 1984: 35).

En otra cita tomada del colaborador del periódico liberal El Español, Juan López Pelegrín hablaba de la conquista de las libertades por parte de las mujeres y hacía hincapié en las limitaciones "La mujer ha conquistado su independencia hasta donde lo han permitido las leyes del pudor y del decoro" (López Pelegrín, 1836: 3) Ana Navarro señalaba en su Antología poética de escritoras de los siglos XVI y XVII: "El pundonor exigido por la sociedad a la mujer española la obligaba al fingimiento de una exagerada virtud, que, sin duda, no siempre tenía" (Navarro, 1989: 51). En la literatura de la época escrita por hombres se presentaba a las mujeres como sujetos que no tenían pasiones, puesto que en las mujeres los amores no eran pasiones sino devaneos, es decir, se invalidaban sus emociones, sus deseos y su imaginación, y se acentuaba la reproducción como la única función propia y apropiada. La mujer no tenía por tanto variedad de afectos, puesto que el deseo le estaba vedado, y solo podía identificarse con un arquetipo prefijado del ángel del hogar, que por supuesto entre sus cualidades no poseía ninguna de carácter intelectual.

Las autoras románticas en cualquiera de los géneros debían subvertir la imagen que de ellas como mujeres se había codificado, debían recurrir a la autoridad de su propia subjetividad y crear sus propias formas de representación, teniendo en cuenta que estas formas debían contenerlas a ellas mismas, es decir, tenían que crear tipos con los que ellas se identificaran y que a la vez erosionaran los existentes eligiendo entre atentar o no contra ellas mismas como sujetos sociales reales. 


\section{SAFO EN LAS POÉticAS ROMÁNTICAS ESPAÑolaS}

La incorporación de las autoras españolas al panorama literario coincidió con el apogeo del movimiento romántico unido a las ideas liberales. Nos referimos a la década de los 40. Estas autoras desearon afirmarse como sujetos a través de la escritura y la realización de este deseo coincidió con años en los que los ataques contra ellas fueron menos virulentos en un principio, aunque con el tiempo esto solo significó un cambio de estrategia. El argumento que se esgrimió fue la inmoralidad de las mujeres que se dedicaban a escribir; la literatura y la virtud femenina eran a todas luces incompatibles. Sin embargo, en esta década numerosas poetas, entre ellas Carolina Coronado, tuvieron la oportunidad de ver sus poemas publicados. Esto se debió entre otros factores al desarrollo de la prensa periódica en la que sus colaboraciones fueron bien acogidas. La diferenciación sexual era real en la práctica y circunscribía a la mujer burguesa al ámbito de lo privado, al considerar la escritura y la publicación de lo escrito como perteneciente al ámbito público, el sujeto femenino incurría en una contradicción, puesto que estaba saliendo de los estrechos márgenes que la sociedad le permitía. Sacar a la luz pública el sujeto individual y la intimidad de éste como proponían los románticos era algo vedado. El romanticismo soñaba con una mujer inmaterial, un ser abnegado al cuidado de la casa y de los hijos, desprovisto de deseos y de pulsiones sexuales. La sexualidad femenina debía estar supeditada a la procreación según la rígida normativa social, así lo explica Judith Walkowitz: "Aunque los médicos discutían acerca del grado de desapasionamiento femenino, estaban en general de acuerdo en atribuir a las mujeres respetables, como máximo, una sexualidad secundaria, de segunda mano, subordinada al placer masculino, carente de autonomía, una pálida imitación del deseo erótico del varón" (Walkowitz, 2000: 390).

La situación en España no era mucho mejor, la construcción cultural de género restringía el ámbito de acción y la función social de la mujer. La sociedad española ejerció un poder represivo que delimitaba los estrechos márgenes de su actuación. El discurso de la domesticidad fue decisivo en el asentamiento de las bases ideológicas de género en la sociedad. Esta construcción ideológica configuraba un prototipo de mujer modelo -la "Perfecta Casada"-basada en el ideario de la domesticidad y el culto a la maternidad como máximo horizonte de realización de la mujer. Desde esta perspectiva, la trayectoria social de las mujeres se limitaba por completo a un proyecto de vida cuyo eje era la familia, en el que su identidad personal propia se desarrollaba a partir del matrimonio y de la maternidad sin que fuera posible crear un proyecto social, cultural o laboral independiente (Nash, 2000: 614). En estos estrechos márgenes se insertan los textos de asunto amoroso que planteaban una cuestión espinosa a las escritoras románticas, tanto en verso o como en prosa. La expresión del sentimiento amoroso y de la pasión, emociones que le habían sido negadas a la mujer en la codificación genérica vigente en esos años, suponía un reto para ellas. Susan Kirkpatrick lo explica de este modo: "Esta exclusión sistemática del sujeto femenino de la plenitud de sentimiento y de la imaginación, incorporó en el yo romántico el problema textual principal al que se enfrentaban las poetas de la década de los cuarenta. A fin de romper los vínculos del ámbito estrecho del sentimiento que les eran permitidos, tenían que encontrar en su estilo algún modo de luchar con esta "masculinización" de la pasión" (Kirkpatrick, 1991: 99). Para estas autoras las ideas románticas y liberales de independencia personal suponían un amargo desengaño, puesto que, incluso en las más avanzadas, se negaba a las mujeres la condición de individuos independientes y con acceso a la esfera pública. El descubrimiento de Safo supuso para las escritoras románticas no solo un modelo como autora de una obra sino también como espejo en el que mirarse como mujer poeta. Para Susan Kirkpatrick "La vinculación de Safo, Corinne y el alma sensible, como elementos de una tradición que autorizaba y conformaba la voz femenina en la poesía, tuvo un efecto importante sobre las primeras poetas románticas en España. Tanto Coronado como Avellaneda incluyen en sus primeras colecciones de poesías imitaciones de Safo, como para identificarse a sí mismas con lo que la poeta griega representaba en España en aquella época (Kirkpatrick, 1991: 86).

¡Feliz quien junto a ti por ti suspira!

Quien el halago de tu risa adora

Y el blando aroma de tu aliento aspira
Qentain

Ventura tanta -que envidioso admira

El querubín que en el empíreo mora-

El alma turba, al corazón devora,

Y el torpe acento, al expresarla, espira.

Ante mis ojos desparece el mundo,

Y por mis venas circular ligero

El fuego siento del amor profundo.

Trémula, en vano resistirte quiero...

De ardiente llanto mi mejilla inundo,

¡Deliro, gozo, te bendigo y muero! (Gómez de Avellaneda: 1850: 163)

Este poema de Gertrudis Gómez de Avellaneda es un buen ejemplo de estos aspectos que señalábamos. La autora lo tituló "Imitando una oda de Safo" y esta imitación utilizandolapalabraqueempleala autora romántica, dalicenciaa Gertrudisparaexpresar sin pudor la pasión que probablemente sí sentía. En el soneto, como corresponde a esta estrofa se va exponiendo el sentimiento de forma gradual hasta culminar en el segundo terceto, puesto que en los dos tercetos se representa el éxtasis erótico hasta llegar al último verso en el que se llega a la muerte, única vía para el placer femenino en la época. En nuestra introducción señalábamos que el conocimiento de Safo en la época era más biográfico que de su obra y que su vida no se desdecía de las normas morales imperantes. Incluso su suicidio como señalaba Carolina Coronado en el texto, antes citado, era visto desde una perspectiva casi heroica, como la poeta extremeña se 
afanaba en explicar que al arrojarse al mar, para cumplir el oráculo con la bendición de los sacerdotes y como ofrenda a un dios, Safo estaba cumpliendo con los preceptos de su religión. Por tanto contar estos hechos suponía cantar una hazaña.

La autora extremeña dedicó dos poemas a este asunto el primero titulado "Los cantos de Safo" y el segundo "El salto de Leucades". El primero es un largo poema narrativo dividido en cuatro cantos en los que Carolina Coronado desempeña el papel de narradora para presentar a Safo que cuenta su historia y para finalizar el texto identificándose con la autora, puesto que ella también siente despecho, al que alude Juan Eugenio Hartzenbusch en su prólogo indicando que solo en esos momentos se expresa con vigor y vehemencia. En este texto son constantes las referencias a la ocupación de Safo expresada metonímicamente con mención reiterada de la lira y la cítara, instrumentos propios de la lírica y la oposición entre belleza y talento, entre conseguir la atención de los hombres y la gloria. En el texto Safo toma la palabra para expresar sus sentimientos que van desde el amor a la envidia, pasando por los celos y el odio. Finalmente habla Carolina para identificarse con los sentimientos de la poeta griega: "Ayer mi seno de placer latía, / y hoy de despecho y de dolor se abrasa..." (Coronado, 1852: 13) El segundo poema está formado por cuatro cuartetos en los que se describe el instante en el que Safo se arroja al mar, explicando cada uno de los detalles del paisaje como si estuviera pintando una escena que termina con su muerte, como ocurría en el poema de Gertrudis Gómez de Avellaneda. De nuevo en el poema presta su voz a Safo que murmura palabras ininteligibles y en el último momento grita el nombre de su amado, para Susan Kirkpatrick (1991) esto simboliza el ahogamiento de la voz poética que se ha atrevido a cantar en una sociedad que niega a la mujer la expresión de su subjetividad:

El sol a la mitad de su carrera

rueda entre rojas nubes escondido

contra las rocas la oleada fiera rompe

el Leucadio mar embravecido.

Safo aparece en la escarpada orilla,

triste corona funeral ciñendo:

fuego en sus ojos sobrehumano brilla,

el asombroso espacio audaz midiendo.

Los brazos tiende, en lúgubre gemido

misteriosas palabras murmurando

y el cuerpo de las rocas prendido

"Faón" dice, a los aires entregando.

Faon" dice, a los aires entregando.

luego en las aguas se desploma y hunde:

el eco entre las olas fluctuante

el sonido tristísimo difunde (Coronado, 1852: 13).

Estos dos casos son los mejor conocidos por tratarse de dos poetas que han gozado de mayor fama que otras autoras del mismo periodo, entre las que Safo también fue una importante fuente de inspiración. La primera de estas románticas a las que nos referiremos es una escritora sevillana llamada Amparo López del Baño de biografía escasamente conocida $\mathrm{a}^{4} \mathrm{y}$ autora de un solo libro que dejó preparado para ser publicado póstumamente, en el que predominan los textos de carácter amoroso. La publicación se la dejó encargada a D. Santiago López Moreno que en 1892 se ocupó de la preparación del volumen y del prólogo. En él daba noticia de la autora y trataba de explicar el motivo por el que no quiso que los poemas en los que exponía los deseos de su alma estuvieran al alcance del público, puesto que en sus textos expresaba su amor con total libertad, sin emplear la modestia o las perífrasis y eufemismos de otras escritoras:

Difícilmente puede pintarse con más sencillez, con más verdad, con más vivos colores lo que hace falta a una mujer amante, que no ha realizado nunca su amor en este mundo; ¡un alma! Pero como por aquí no andan las almas sin la envoltura corporal quien pedía un alma pedía también un cuerpo, y como es sabido que en el amor no impera la ley de los semejantes siendo cosa notoria que la oposición de los contrarios produce la armonía, bien se refleja en tan sentido lamento el vacío insustituible del amor humano que en su alma sentía (López del Baño, 1892: 10).

Entre ellos destaca el poema titulado "Cleobulina" dedicado a Safo, aunque por este nombre se conocía a otra escritora, la historia que se desarrolla en él es la de Safo. Su presencia en todos los poemarios de la época refuerza la idea de que ante la falta de figuras femeninas a las que tomar como modelo, las autoras tienen que volver sus ojos hasta la antigüedad grecolatina y tomar como modelo a la poeta griega. Se trata de un largo romance dividido en varios fragmentos. En el primero de ellos la presenta: “Célebre en la Grecia un día / brilló en su frente radiosa / de la cantora de Lesbos / la deslumbrante corona: / mas jay! el laurel que abrasa / cuanto con sus ramas toca, / no perdonó ni aún la suya" [...]. En estos primeros versos expone un asunto que tratan otras autoras y sobre el que insiste más adelante: la gloria para la mujer tiene una contrapartida y conseguirla lleva aparejada la desgracia, de hecho estos versos son casi una advertencia:

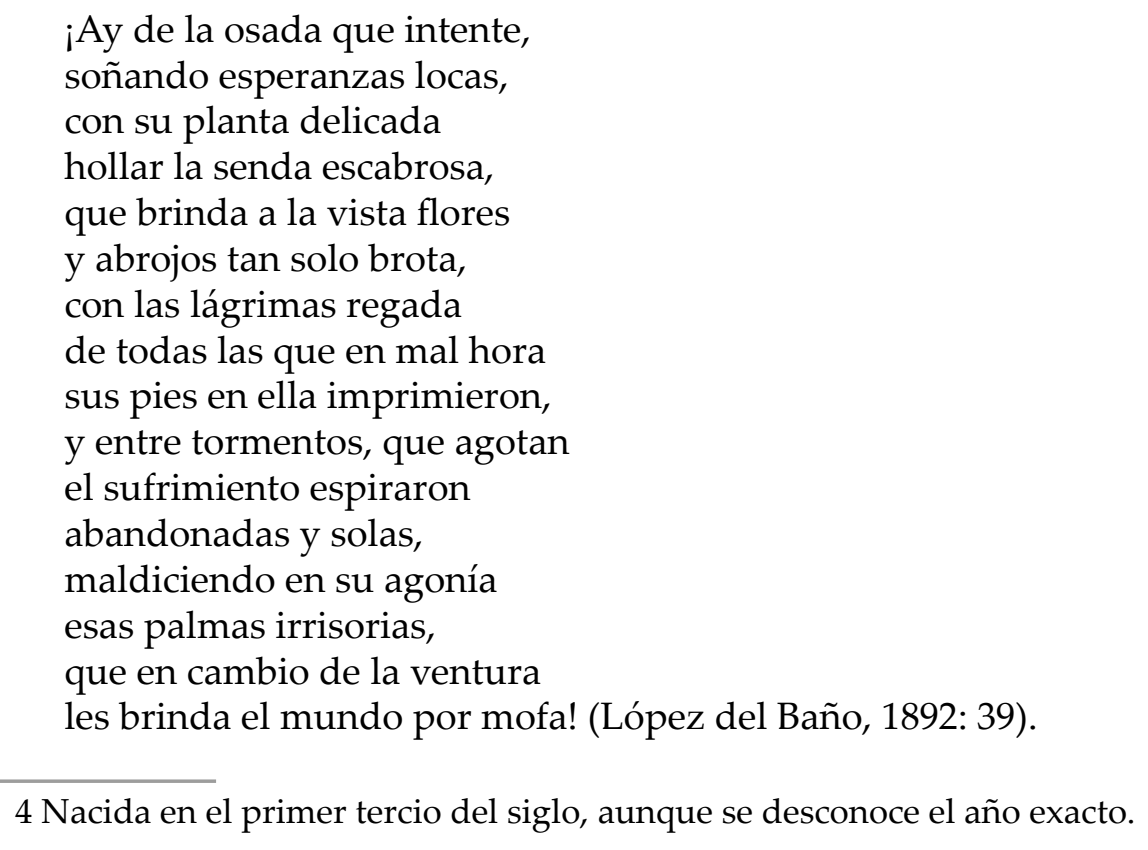


Tras esto nos presenta la figura de una mujer que vaga por las alamedas y que ya no canta aunque esté sentada sobre laureles, hace referencia al despecho y al vano intento que hace de cantar acompañada de la lira. En la segunda parte indica que la vieron sobre unas altas rocas de Colona, la referencia geográfica indica un lugar que es parte de Atenas probablemente la autora lo utilice de forma metonímica, y que desde unas playas remotas se lanzó al turbulento mar. A partir de la tercera parte toma la palabra Safo para despedirse de la vida y recuerda cuáles son los motivos que la han llevado hasta allí:
¡Sueños de amor y poesía!
¡llusiones seductoras
de mis años infantiles!
Dulces y vagas memorias,
¡de un mundo que no ha existido
más que aquí en mi mente loca!
Sostenedme en vuestros brazos
sembrad mi lecho de rosas;
borrad todos mis recuerdos.
haced que las dichas todas
a la luz de la esperanza,
halaguen mi última hora.
Arrancad el dardo agudo
que mi corazón destroza..
y en el seno de la muerte,
donde la eterna paz mora,
ay! reclinad mi cabeza,
que la desventura agobia...(López del Baño, 1892: 39).

En esta primera generación de escritoras encontramos a Rogelia León, nacida en Granada en 1828. En 1857 recogió sus poemas en una colección titulada Auras de la Alhambra, que contenía un largo poema narrativo titulado “¡Pobre Safo!”. La autora granadina era académica profesora del Liceo de Granada, socia del Círculo Científico, Literario y Artístico de Málaga, y socia de mérito de la Academia Científico Literaria de Madrid y podemos suponer que no solo conocía la figura de la autora griega, puesto que el poema lleva una cita suya: "Mira por fin compasiva / las lágrimas que derramo, / y haz que ese ingrato a quien amo / se apiade de mi dolor...". En él se volvían a recrear los instantes últimos antes del suicidio, la invocación a Venus, la despedida de Faón y hasta de su rival a la que le pide que lo quiera tanto como ella. Sin embargo hay un detalle en el que se diferencia de los demás, Safo reniega de su condición de poeta en unas estrofas que se encuentran hacia la mitad del texto:

$\ldots$ ¿Dónde el talento está? ¿Por qué me aplaude

doquier el grito general de Lesbos

no he podido trocar su alma de hielo?

¡Maldición a los lauros y coronas

que espinas guarda y sutil veneno,

una existencia de voraz tormento!... (León, 1857: 74).
En la segunda generación de poetas románticas se sitúa Eduarda Moreno. Susan Kirkpatrick indica en su edición Antología poética de escritoras del siglo XIX, que son muy escasos los datos existentes de esta poeta granadina que fue académica profesora de la Academia de Bellas Artes de Granada y colaboró en revistas y coronas. En su primer libro de poemas, publicado en 1857 y titulado Ayes del alma, incluyó un largo poema titulado "Safo" del que la autora americana seleccionó la última sección para su antología. El texto lleva una cita de la poeta de Lesbos: "Ya sumergiose la luna; / ya las pléyades cayeron". Se trata de un poema descriptivo en el que el paisaje tiene un gran protagonismo, especialmente la luna oculta entre las nubes, un paisaje típicamente romántico que sirve a la voz poética, que representa a Safo, para preguntarse por el porvenir, por el día de mañana que quizás no se conozca y la única certeza la de la muerte "Solo una tumba silenciosa y fría / nuestros tristes delirios calmará". De nuevo vemos, cómo la muerte, es el único fin para la mujer que canta y para la que ama.

Desde el inicio del poema la autora busca la complicidad de los elementos de la naturaleza, de las brisas, las olas, las flores, etc., para que vayan hasta Faón y le digan que lo sigue amando, al final del poema es ella la que lo llama, la que se dirige a él sin intermediarios para declararle la pasión que la consume, por tanto el uso de palabras como "placer" o "ardiente", que habría planteado problemas a estas autoras de referirse a sus propios sentimientos, no supone ninguna dificultad si se refiere a la poeta griega:

¡Ven, ven, Faón! ¡La luna sumergiose!

¡Mi corazón te llama con afán!

Un suspiro, un suspiro de tus labios!

Una dulce palabra, nada más.

Yo en cambio te daré mi vida toda,

y un mundo de placer y de verdad

y el infinito fuego de mi alma

ardiente como el seno del volcán (Kirpatrick, 1992: 255).

La siguiente poeta a la que nos referiremos es Mercedes de Velilla, también sevillana y perteneciente a la tercera generación de escritoras románticas, puesto que nació en 1852. En el soneto titulado "Safo" recordaba a la poeta griega. En esos versos aparecen varios aspectos fundamentales en sus poemas: la visión de la mujer, y la pena y el dolor real como materia poética. Mercedes presenta a la poeta griega como un personaje romántico propio de una leyenda de Bécquer. En este texto se hace referencia de nuevo a su papel de poetisa, al igual que en el poema de C. Coronado, aunque en este caso su canto es triste por su "doliente cuita", es decir, por su malogrado anhelo. En el texto "Los cantos de Safo" el ejercicio de la poesía lleva siempre adjetivos positivos "tierna lira", "deliciosos tonos", etc. De nuevo el mar cobra protagonismo para convertirse en una tumba inmensa, recordemos que las tumbas, los cementerios, etc., formaban parte de los escenarios en los que se ambientan numerosos textos de este periodo:

Una mujer, como visión o hada, 
en la roca de Léucades se agita;

retratase en su faz pena infinita,

la desesperación en su mirada.

Es Safo, la poetisa enamorada

que el arpa hiere con doliente cuita

y en su última canción llora y palpita

la pasión infeliz y desdeñada.

Tú fuiste, oh mar, de su dolor testigo,

y en tu seno aquel cuerpo recibiste,

que al sacro numen y al amor dio abrigo.

Así, en tu inmensidad tumba le diste;

en tus amargas olas, llanto amigo,

y en tu eterno rumor, funeral triste (Velilla, 1918: 29).

A esta tercera generación pertenece Josefa Ugarte Barrientos nacida en 1854 en Málaga, recibió una excelente formación en literatura e historia, autora teatral, prosista y poeta. Su obra poética fue recogida por su hijo póstumamente en el volumen Poesías selectas. A este libro pertenece "Saffo" un soneto que puede compararse a los textos ya citados, puesto que en él se trata de nuevo el momento en el que la poeta griega se lanza al mar desde la roca de Leucades, nos encontramos en este caso con una protagonista que llora con desesperación en el momento de su muerte, es cierto que en casi todos los poemas Safo muestra su tristeza y llora, como acabamos de ver, pero en este caso lloran incluso las musas, Safo llora de amor y su fin es irremisiblemente la muerte:

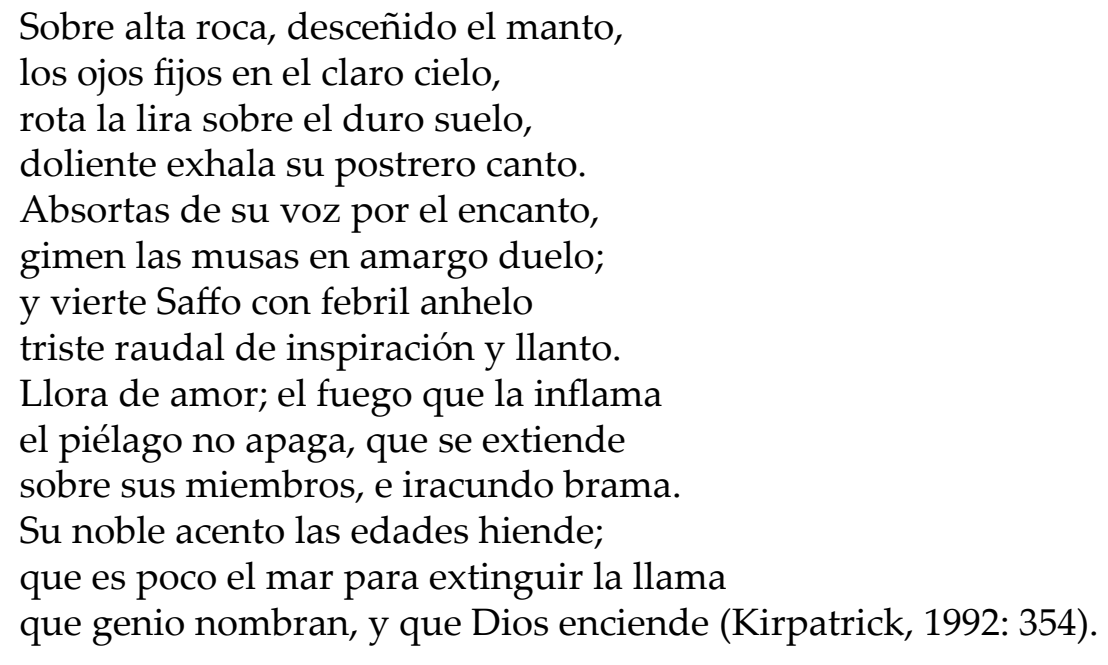

Sobre alta roca, desceñido el manto,

los ojos fijos en el claro cielo,

rota la lira sobre el duro suelo,

doliente exhala su postrero canto.

Absortas de su voz por el encanto,

gimen las musas en amargo duelo;

y vierte Saffo con febril anhelo

triste raudal de inspiración y llanto.

Llora de amor; el fuego que la inflama

el piélago no apaga, que se extiende

sobre sus miembros, e iracundo brama.

Su noble acento las edades hiende:

que es poco el mar para extinguir la llama

que genio nombran, y que Dios enciende (Kirpatrick, 1992: 354).

\section{Conclusiones}

Durante los siglos XVIII y XIX la obra de Safo se difundió gracias a las traducciones que se publicaron de esta autora en antologías de poetas griegos, la fama que la autora ya tenía en su época y después de su muerte como atestiguan los testimonios de los escritores griegos también había perdurado. Su figura envuelta en el misterio de los escasísimos datos conocidos sobre su biografía supuso para las escritoras románticas un espejo en el que mirarse como mujeres poetas así como también un referente que tomar como principio de autoridad. Su amor apasionado y no correspondido por Faón fue una fuente inspiración, que las autoras de este periodo supieron aprovechar también para expresar sus propios sentimientos puestos en los labios de la poeta griega.

En una sociedad en la que la mujer tenía muy bien delimitado el ámbito de su actuación a la esfera de lo privado, debiendo encarnar al arquetipo romántico del ángel del hogar, las autoras de este periodo encontraron un personaje femenino que legitimaba sus ansias de ocupar también el espacio de lo público y la expresión de la pasión, aunque ambas llevasen consigo la muerte. Una muerte gloriosa como en el caso de Safo merecía ser cantada por quienes, como ella, eran mujeres, poetas y amantes. Por todo ello podemos encontrar numerosos ejemplos de poemas en los que las autoras románticas se hicieron eco de sus amores y de su suicidio, así escribieron poemas dedicados a ella Gertrudis Gómez de Avellaneda, Carolina Coronado, Amparo López del Baño, Rogelia León, Eduarda Moreno, Mercedes de Velilla y Josefa Ugarte.

\section{REFERENCIAS BIBLIOGRÁFICAS}

Berrero Pérez, Ó., "Imágenes de Safo en la literatura Española (II). El siglo XIX", en Cuadernos de Ilustración y Romanticismo, n.. 12, págs. 61-75, 2004.

----, "Imágenes de Safo en la literatura Española (I). El siglo XVIII", en Dieciocho, n.․ 28, 2005 Coronado, C., “Los genios gemelos. Primer paralelo: Safo y Santa Teresa de Jesús", en el Semanario pintoresco español, 1850.

---, Poesías de la señorita Carolina Coronado. Madrid, 1852

Díaz Plaja, G., Introducción al estudio del romanticismo español. Espasa-Calpe, S. A. Austral. Madrid, 1980 Gómez de Avellaneda, G., Poesías. Delgras Hermanos. Madrid, 1850.

González González, M., “Versiones decimonónicas en castellano de la Oda a Afrodita (Frg. 1 Voigt) y de la Oda a una mujer amada (Frg. 31 Voigt) de Safo" en Cuadernos de Filología Clásica: estudios griegos e indoeuropeos. 273, vol. 13, págs. 273-312, 2003.

Kirkpatrick, S., Las Románticas. Escritoras y subjetividad en España, 1835-1850, Cátedra, Feminismos, Madrid, 1991.

----, Antología poética de escritoras del siglo XIX, Castalia, Biblioteca de escritoras, Madrid, 1992. León, R., Auras de la Alhambra. Imprenta y librería de D. José M. Zamora. Granada, 1857.

López del Baño y Alfaya, A., Poesías, R. Velasco Imp. Rubio 20, Madrid, 1892.

López Pelegrín, J., “De las mujeres. Primer artículo” en El Español, 14 de junio de 1836, pp. 3-4.

Mayoral, M., Escritoras románticas españolas, Mayoral, M. (Coord.), Fundación Banco Exterior, Madrid, 1900 
Morilla Palacios, A., “Mercedes Matamoros y Safo de Lesbos”, en Foro de educación. N. 9, págs. 279-296, 2007.

Nash, M., “El discurso de la domesticidad y la definición del trabajo de las mujeres” en Duby, Georges y Perrot

M., Historia de las mujeres. 4. El siglo XIX, Taurus, Madrid, 2000.

Navarro, A., Antología poética de escritoras de los siglos XVI y XVII, Castalia, Madrid, 1989.

Poovey, M., The Proper Lady and the Woman Writer: Ideology as Style in the Works of Mary Wollstonecraft, Mary Shelley and Jane Austen, University of Chicago Press, Chicago, 1984. Safo, Poemas y testimonios, Edición de Aurora Luque. Acantilado, Barcelona, 2004. Valis, N. M., "La autobiografía como insulto", en La autobiografía en la España contemporánea, en Anthropos, n. 125, Anthropos, Barcelona, 1991.

Velilla y Rodríguez, M. de, Poesías. Ayuntamiento de Sevilla. Sevilla.1918.

Walkowitz, J. R., “Sexualidades peligrosas” en DUBY, Georges y PERROT, Michelle (2000): Historia de las mujeres. 4. El siglo XIX, Taurus, Madrid, 2000. 